\title{
Improvement in Performance of the Sulphuric Acid Transport Installation through Modification of Flow Characteristics Using Electric Actuators
}

\author{
Stanisław Gil ${ }^{1, *(D)}$, Mariusz Wnęk ${ }^{1}$ and Robert Łudzień ${ }^{2}$ \\ 1 Faculty of Engineering Materials, Silesian University of Technology, Krasińskiego 8, 40-019 Katowice, Poland; \\ mariusz.wnek@polsl.pl \\ 2 AUMA Poland Ltd., Komuny Paryskiej 1D, 41-219 Sosnowiec, Poland; ludzienr@auma.com.pl \\ * Correspondence: stanislaw.gil@polsl.pl; Tel.: +48-32-603-4221
}

Citation: Gil, S.; Wnęk, M.;

Łudzień, R. Improvement in

Performance of the Sulphuric Acid

Transport Installation through

Modification of Flow Characteristics

Using Electric Actuators. Energies

2021, 14, 2797. https://doi.org/

$10.3390 /$ en14102797

Academic Editor: Galih Bangga

Received: 5 March 2021

Accepted: 5 May 2021

Published: 13 May 2021

Publisher's Note: MDPI stays neutral with regard to jurisdictional claims in published maps and institutional affiliations.

Copyright: (c) 2021 by the authors. Licensee MDPI, Basel, Switzerland. This article is an open access article distributed under the terms and conditions of the Creative Commons Attribution (CC BY) license (https:/ / creativecommons.org/licenses/by/ $4.0 /)$

\begin{abstract}
The paper presents a flow model of the installation for tank car filling with sulphuric acid (VI). For the mathematical modelling of the flow process in the industrial installation, a model diagram of the object and experiments carried out during the installation work were applied. The analysis of specific experimental series showed unusual shapes of mass flow characteristics vs. the valve opening level (too wide hysteresis), which markedly deviated from typical flow characteristics that are found in standards and literature. As a result of flow modelling in the sulphuric acid installation, a better-shaped characteristic was presented that should be obtained based on the measuring system values in the absence of the inertia-related error. In the experiments carried out according to the selected procedures, effects of the actuator speed on the characteristics of interest were determined. It was observed that the use of a "slower" actuator (i.e., longer transition time) narrows the characteristics in terms of a reduced difference in flow readings between the valve opening and closing courses. In the specified research procedure for the real flow characteristics, effects of the measurement transducer dynamics in the flow meter on the characteristic course were assessed. It was demonstrated that a faster transducer enabled closer flow recordings to the valve nominal characteristics. The variable speed can improve the positioning precision, with the use of the lowest possible speed rule directly before the positioning point.
\end{abstract}

Keywords: fittings; flow sensor; characteristics of actuator

\section{Introduction}

Flows of various fluids are typical of almost all production processes. They often require careful control of the flow type as well as its measurements and management. This is particularly important when the fluid to be transported constitutes an environmental hazard. Flow control systems are required to maintain stable flow and to change it smoothly when the installation operates periodically as it is in the case of tank filling devices.

With the flow control using throttling valves, significant problems with the control quality (positioning in particular) can be observed, especially during the initial step of valve opening. Moreover, while the valve is being opened and closed, negative effects may occur such as water hammer or pressure pulsations that destructively influence the devices and electronic equipment for measurements and control [1,2]. A key issue here is proper control of the fluid flow throughout the flow duration, emphasising its initial and final phases as well as breaks due to device malfunction. This refers to ensuring a relatively short duration of these phases and stable flow without undesirable effects [1,3-6] that may be observed if the control valve is opened and closed too quickly. The problem is particularly important when the transported technological fluid constitutes an environmental hazard.

The actuator design determines its basic flow characteristic defined as a relationship between the fluid flow and the valve opening, with a stable pressure drop. It is commonly 
described by the flow coefficient $K v$, which is an international value to be determined experimentally $[7,8]$. The same design of the actuator also applies to the real flow characteristic that is not recorded in the steady state contrary to the basic performance. Hence, it contains the dynamic factors that are not presented overtly.

The aim of this paper is to present:

- a developed flow model of the tank car filling installation for sulphuric acid (VI) and the flow characteristic of another, better shape that should be obtained based on the measuring system values in the absence of the inertia-related error;

- factors that quite covertly modify the valve flow characteristics to make it inconvenient for the control and positioning system leading to difficulties in proper technological process conduct where the quality depends on appropriate flow control;

- a discussion about techniques of precise positioning and avoiding (by means of electric actuators) undesirable secondary flow phenomena such as pumping, water hammer, cavitation, pulsation, and wave.

\section{Industrial Tests}

The Materials and Methods should be described with sufficient details to allow others to replicate and build on the published results. Please note that the publication of your manuscript implicates that you must make all materials, data, computer code, and protocols associated with the publication available to readers. Please disclose at the submission stage any restrictions on the availability of materials or information. New methods and protocols should be described in detail while well-established methods can be briefly described and appropriately cited.

Each stand is equipped with a filling head and hoses that deliver sulphuric acid (VI) to the head. The head is mounted on the crane and connected with the pipeline installation that supplies the fillers. Each filler consists of the following components: a manual valve, inductive flow meter, and a gate valve with an electric actuator that is signal-controlled from the control room. The pipeline installation, from the delivery port of the vertical feed pump to the filling hoses, is made of acid-proof steel while the hoses themselves are made of composite material. The fillers are supplied by a vertical pump plunged in the pump tank. The acid is delivered via the pipeline to the collector located under the filling platform. The top point of the pipeline is fitted with a vent valve. The collector is connected with each filler via the distributing pipes. The collector is equipped with a draining valve and a control flashlight. The nominal acid flow rate for each filler is $30 \mathrm{~m}^{3} / \mathrm{h}$. Its maximum operating pressure is approx. $2 \times 10^{5} \mathrm{~Pa}$. Figure 1 presents the technological diagram of the installation for the filler used for the experiments. This section is representative for the whole installation due to the same design of the other fillers.

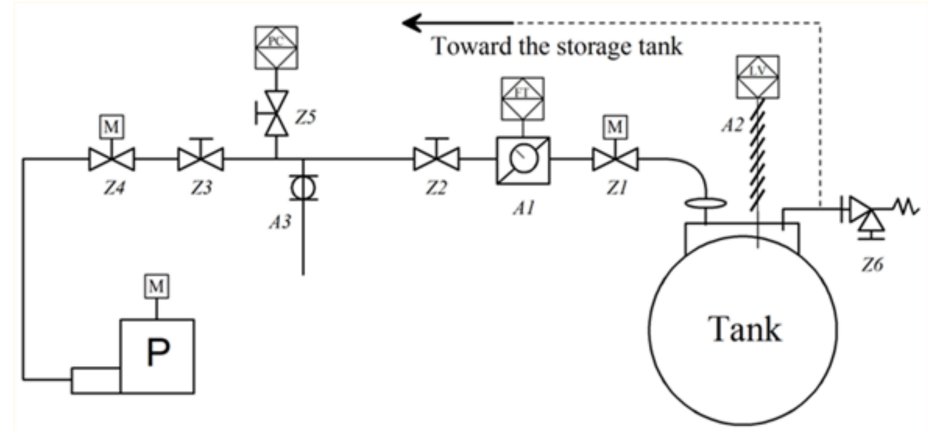

Figure 1. Technological diagram of fillers for sulfuric acid (VI), where: A1-flow measurement, DN 65; A2-emergency level sensor; A3-ball valve, DN65; P-flow meter, DN 65; Z1—flap valve, DN 200; Z2-flap valve, DN 65; Z3 - ball valve, DN 65; Z4 -ball valve, DN 80; Z5—ball valve, DN 25; Z6-safety valve, DN 15. 
The air displaced by the acid from the tank is delivered to the pump tank via the pipeline. The pressure inside the tank is maintained at a slightly lower level than that of the acid reaching the filling head.

In the experiments, the AUMA SGR 07.1 fixed-speed actuator was applied. The measured parameters: time (ms), valve opening level (\%), and sulfuric acid (VI) mass flow rate $(\mathrm{kg} / \mathrm{min})$ were recorded by the computer system. To save and store the data, the "Omron" software programme was developed in Visual Studio 6.0. The programme cooperated (via the COM1 serial port) with the OMRON NS10-TV01B-V2 programmable controller, which manages the acid filling process. For safety reasons, low-pressure flows are usually set for hazardous substances and the control valve is not fully open. The maximum opening level for the valve was programmed at $50 \%$. The measuring sensor of the PROMAG 50P flow meter enabled recording of the measurement results with an average sampling time of $111 \mathrm{~ms}$. Nineteen experiments were carried out. Data containing up to over 600 measured values were collected during each experiment.

Figure 2a presents results of 19 experiments assessing the mass flow rate vs. the valve opening level that aimed at verifying result repeatability. These characteristics were obtained for the following measuring procedure: the valve transition from the $0 \%$ to approx. $45 \%$ opening level, stopping for approx. $40 \mathrm{~s}$ and closing to $0 \%$, followed by stopping again for approx. $40 \mathrm{~s}$. Unusual shapes of the characteristics recorded (wide hysteresis) were observed that markedly deviated from the standard and literature flow characteristics [9-11]. Figure $2 \mathrm{~b}$ is a graphical illustration of the flow vs. the valve opening level for three experiments (using the fixed-speed actuator) where the value of actuator stopping time was changed at the $30 \%$ valve opening level. The values were $40 \mathrm{~s}, 17 \mathrm{~s}$, and $0 \mathrm{~s}$ for the experiments 1,2, and 3, respectively. Using a variable-speed actuator fitted with the function of speed change before the positioning point, the characteristics can be appropriately profiled and the valve position can be precisely set.

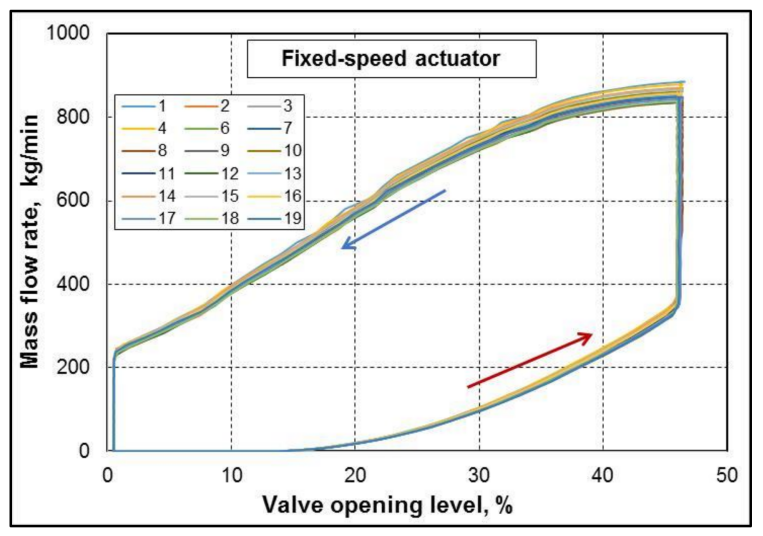

(a)

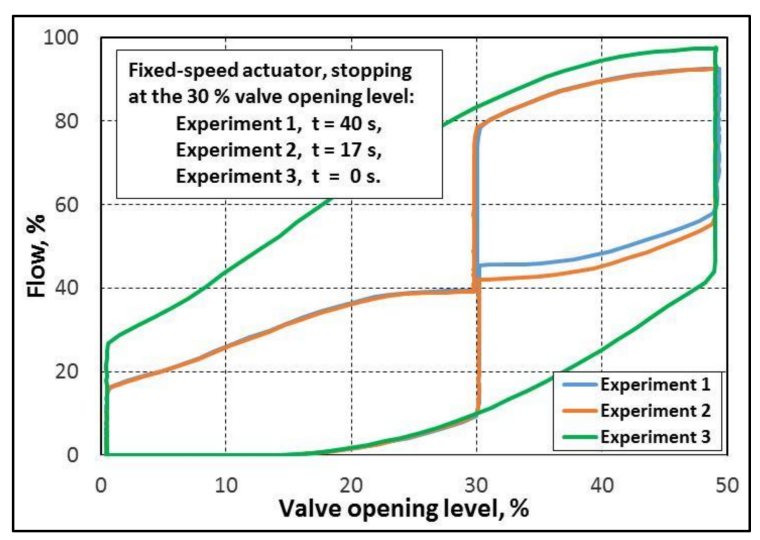

(b)

Figure 2. Mass flow vs. valve opening level: (a) results of 19 experiments; (b) experiments with stopping of actuator.

Normative testing is carried out in the system of manual positioning, which ensures flow stabilisation at the measuring point; the measurements are taken every $2 \%$ to $5 \%$. The authors carried out the measurements every approx. $110 \mathrm{~ms}$ resulting from continuous movement of the actuator and based on this, they developed new (with the continuous actuator movement) flow characteristics (similarly, wide hystereses were recorded by Cui et al. [12]). They studied effects of the opening and closing process on flow performance and internal characteristics. The researchers did not comment on these unusual phenomena, but only focused on the analysis of pressure changes in front of and behind the valve as well as turbulence in this area. The set of characteristics presented suggests improper adjustment of the speed of actuator with the valve and dynamics of the fluid flow measuring system. Based on the catalogue charts for the control valve mounted in the research installation, 
a dead angle of approx. $11^{\circ}(12.2 \%)$ can be observed and the agent flow only starts after exceeding this value.

The analysis of Figure 2a shows that during the opening procedure, the flow occurs not earlier than at the approx. $15 \%$ opening level, but this fact is not at all seen for the closing procedure. It can be noted that when the dead angle of $11^{\circ}$ is exceeded during the closing procedure, the flow is still recorded despite its physical absence as the valve has been closed. This clearly indicates the important effect of the measurement system inertia on the measurement data obtained and the process of correct control to ensure proper flow parameter management.

\section{Modelling of Flow in the Sulfuric Acid Installation}

Considering the fluid type as well as the size and location of the installation, the fluid was assumed to be incompressible for pressure loss determination purposes while the density or specific gravity were practically negligible. As a result of a frequency converter (with the control system) mounting on the pump, stable gauge pressure of the source is maintained at approx. 2 bar regardless of the process performance. The gauge pressure in the transport tank is constant within the whole range of the distribution system performance and equals approx. 0.1 bar. The control valve operates within $0 \%$ to $45 \%$ of its opening level. The maximum mass flow rate recorded during the experiments (with the maximum opening of the actuator valve) was $857 \mathrm{~kg} / \mathrm{min}$. For each system element, flow-related pressure loss is observed, but if considered as a whole, the overall pressure loss is taken into account, which is described as the field characteristics $\Delta p_{S}=f(\dot{m})$, where: $\Delta p_{S}$-overall field pressure loss, $\mathrm{Pa} ; \dot{m}$-mass flow rate, $\mathrm{kg} / \mathrm{s}$. The source, e.g., a pump, ventilator, or a pressure control $\left(p_{Z}\right)$, has its own flow characteristics defined as $p_{Z}=f(\dot{m})$ and it must be properly selected to compensate for the installation pressure losses and to ensure technological efficiency, i.e., it must meet the following equation:

$$
p_{Z}(\dot{m})=\Delta p_{S}(\dot{m})+\Delta p_{N}(\dot{m})+p_{o d b}
$$

where: $\Delta p_{N}$-pressure drop on the actuator, $\mathrm{Pa} ; p_{o d b}$-receiver pressure, $\mathrm{Pa}$. The valid model of the installation system is Equation (1), where the specific elements should be determined.

Based on the obtained basic flow characteristics, measurement data, and assumptions, Equation (2) was derived to enable calculations of pressure drop in the actuator during the maximum flow, which is the basis for solving the system of equations that describe pressure losses in individual field elements. The component $f_{\text {aprox }}$ of the equation is a function that approximates the control valve flow characteristics:

$$
\Delta p_{N}\left(\dot{m}_{\max }, \varphi\right)=\left(\frac{\dot{m}_{\max }}{A_{N^{\varepsilon}}}\right)^{2} \frac{1}{D_{1}^{2} D_{2} \rho} f_{\text {aprox }}
$$

where: $\dot{m}_{\max }$-maximum mass flow rate, $\mathrm{kg} / \mathrm{h} ; A_{N}$-nominal flow surface area for the valve, $\mathrm{m}^{2} ; \varepsilon$-expansions; $D_{1}$-numerical coefficient $\left(D_{1}=0.101, \mathrm{~s} / \mathrm{m}\right) ; D_{2}$-numerical coefficient $\left(D_{2}=25.45 \times 10^{8} \mathrm{~m}^{2} / \mathrm{h}^{2}\right) ; \rho$-fluid density, $\mathrm{kg} / \mathrm{m}^{3}$. Based on this equation, the estimated pressure drop in the control valve for the maximum flow is approx. $30.26 \mathrm{kPa}$.

A general quadratic equation $p_{Z}=-a_{1} \dot{m}^{2}+b_{1} \dot{m}+c_{1}$ was assumed as the source characteristics $p_{z}$. In the case of the installation of interest, the source is a pump fitted with a pressure control, which means constant-value characteristics, so coefficients equal zero and $\mathrm{c}_{1}=200 \mathrm{kPa}$.

Consistent with the model diagram of selected installation path, we present the individual element characteristics results in the field characteristics. For each of these elements, the continuity equation and Bernoulli's equation are met in relation to the input cross-section 1 and the output cross-section 2:

$$
\alpha \frac{\rho w_{1}^{2}}{2}+p_{1}+\rho g z_{1}=\alpha \frac{\rho w_{2}^{2}}{2}+p_{2}+\rho g z_{2}+\Delta p_{s t r_{1-2}}
$$


where: $\alpha$-Saint-Venant's coefficient (it is $\alpha=1$ based on the accepted assumptions; $w_{1}$, $w_{2}$-fluid flow rate across the sections 1 and $2, \mathrm{~m} / \mathrm{s} ; p_{1}, p_{2}$-fluid pressure across the sections 1 and 2, $\mathrm{Pa} ; \mathrm{g}$-gravitational acceleration, $\mathrm{m} / \mathrm{s}^{2} ; z_{1}, z_{2}$-location height (from the reference level) of the elements across the sections 1 and $2, \mathrm{~m} ; \Delta p_{s t r_{1-2}}$-pressure losses between the cross-sections 1 and 2, Pa.

For each system element, flow resistance is taken into account, which affects pressure loss. Considering hydraulically smooth pipes and the Reynold's number $\operatorname{Re}>4000$ as well as pipe relative roughness $\mathrm{e} \leq \mathrm{e}_{\text {gran }}$, the friction coefficient $\lambda$ can be calculated using the Prandtl-Karman equation $[13,14]$ :

$$
\frac{1}{\sqrt{\lambda}}=2 \log \frac{\sqrt{\lambda} \operatorname{Re}}{2.51}
$$

Based on the catalogue charts for the control valve mounted in the research installation for sulfuric acid distribution (C-type NTC PN16 ball valve), the $K_{V}(\varphi)$ was developed. Using the above flow characteristics and the relationship between $K_{V}(\varphi)$ and local resistance $Z_{N}(\varphi)$, the equation for basic flow characteristics was derived regarding the analysed valve (Equation (5)), which was determined by means of the regression method with the coefficient of determination $\mathrm{R}^{2}=0.999$ :

$$
Z_{N}(\varphi)=a \varphi^{b} e^{-c \varphi}
$$

where: $a=88,954\left({ }^{\circ}\right)^{1,2}, b=-1.2, c=1.23 \times 10^{-1} 1 /^{\circ}$.

For turbulent flow, the flow $\dot{m}$ of the fluid passing through the valve is described by the equation where flow coefficient changes are taken into account:

$$
\dot{m}=D_{1} K_{V}(\varphi) \varepsilon \sqrt{\Delta p_{N} \rho}
$$

Consistent with our assumptions for the first system element (E1), and limited by the control cross-sections 1 and 2, for a given opening angle $\varphi$ regarding the control valve, output parameters in the section 2 should be determined as the input parameters for the next element (E2):

$$
\left\{\begin{array}{c}
A_{1} \cdot w_{1} \cdot \rho_{1}=A_{2} \cdot w_{2} \cdot \rho_{2} \\
\frac{\rho w_{1}^{2}}{2}+p_{1}+\rho g z_{1}=\frac{\rho w_{2}^{2}}{2}+p_{2}+\rho g z_{2}+\Delta p_{s t r_{1-2}} \\
\Delta p_{s t r_{1-2}}=\lambda \frac{L}{d} \frac{\rho w_{1}^{2}}{2} \\
\frac{1}{\sqrt{\lambda}}=2 \log \frac{\sqrt{\lambda} \frac{R e}{2.51}}{}
\end{array}\right.
$$

where: $L$-pipeline length, $\mathrm{m}$; $d$-pipeline diameter, $\mathrm{m}$.

Then, for the next system element (E2), which is a flap check valve, the following system of equations should be solved:

$$
\left\{\begin{array}{c}
A_{2} \cdot w_{2} \cdot \rho_{2}=A_{3} \cdot w_{3} \cdot \rho_{3} \\
\frac{\rho w_{2}^{2}}{2}+p_{2}+\rho g z_{2}=\frac{\rho w w_{3}^{2}}{2}+p_{3}+\rho g z_{3}+\Delta p_{s t r_{2-3}} \\
K_{V}(\varphi)=A_{N} \sqrt{\frac{D_{2}}{Z_{N}(\varphi)}} \\
\Delta p_{s t r_{2-3}}=\left(\frac{9.9 \dot{m}}{K_{V}(\varphi) \varepsilon}\right)^{2} \frac{1}{\rho}
\end{array}\right.
$$

where 0.9 is expressed in $\mathrm{m} / \mathrm{s}$.

The third element (E3) and the other straight system sections are described by Equation (7), with the friction coefficient $\lambda$ determined according to the standard [13] depending on the flow type specified by the Reynold's number. 
The fourth element (E4), i.e., the $90^{\circ}$ elbow of a given bend radius (for $R / d>1.5$ and smooth pipes), is described by the following system of equations:

$$
\left\{\begin{array}{c}
A_{4} \cdot w_{4} \cdot \rho_{4}=A_{5} \cdot w_{5} \cdot \rho_{5} \\
\frac{\rho w_{4}^{2}}{2}+p_{4}+\rho g z_{4}=\frac{\rho w_{5}^{2}}{2}+p_{5}+\rho g z_{5}+\Delta p_{s t r_{4-5}} \\
\Delta p_{s t r_{4-5}}=\left(0.0175 \lambda \frac{R}{d} \alpha+0.21 \sqrt{\frac{d}{R}}\right) \frac{\rho w_{4}^{2}}{2}
\end{array}\right.
$$

where $R$ and $\alpha$ are determined according to the standard [13]. For $90^{\circ}$ elbows with $R / d>$ 1.5 and rough pipes, the pressure drop is determined as follows:

$$
\Delta p_{\operatorname{str}_{A-B}}=\left(0.0175 \lambda \frac{R}{d} \alpha+0.21 C \sqrt{\frac{d}{R}}\right) \frac{\rho w_{B}^{2}}{2}
$$

with standardised $C$ parameter values presented in [13] for bent elbows $0^{\circ}<\alpha<180^{\circ}$. The conical confusor (E17 and E19) is described by the following system of equations:

$$
\left\{\begin{array}{c}
A_{17} \cdot w_{17} \cdot \rho_{17}=A_{18} \cdot w_{18} \cdot \rho_{18} \\
\frac{\rho w_{17}^{2}}{2}+p_{17}+\rho g z_{17}=\frac{\rho w_{18}^{2}}{2}+p_{18}+\rho g z_{18}+\Delta p_{s t r_{17-18}} \\
\Delta p_{s t r_{17-18}}=\frac{\lambda l}{4 d}\left[1+\frac{D}{d}+\left(\frac{D}{d}\right)^{2}+\left(\frac{D}{d}\right)^{3}\right] \frac{\rho w_{17}^{2}}{2}
\end{array}\right.
$$

where $d, D$, and $l$ are defined according to the standard [13]. The conical diffuser for $0^{\circ}<\alpha$ $<40^{\circ}$ (E28) is described as follows:

$$
\left\{\begin{array}{c}
A_{28} \cdot w_{28} \cdot \rho_{28}=A_{29} \cdot w_{29} \cdot \rho_{29} \\
\frac{\rho w_{28}^{2}}{2}+p_{28}+\rho g z_{28}=\frac{\rho w w_{29}^{2}}{2}+p_{29}+\rho g z_{29}+\Delta p_{s t r_{28-29}} \\
\Delta p_{s t r_{28-29}}=3.2 \operatorname{tg} \frac{\alpha}{2} \sqrt[4]{\operatorname{tg} \frac{\alpha}{2}}\left(1-\frac{d^{2}}{D^{2}}\right)^{2}+\frac{\lambda}{8 \sin \frac{\alpha}{2}}\left[1-\left(\frac{d^{2}}{D^{2}}\right)^{2}\right]
\end{array}\right.
$$

The equations describing the particular technological field elements are solved for a specific valve opening level. Based on the obtained results for the specific angle $\varphi$, the n-element field characteristics can be determined following the equation:

$$
\Delta p_{S}(\varphi)=\sum_{i=1}^{n-1} \Delta p(\dot{m})_{s t r_{i-(i+1)}}
$$

It should be noted that despite the defined element characteristics that form the final operational characteristic, Equation (1) must be ultimately met.

\section{Results of Flow Modelling in the Sulfuric Acid Installation}

For the mathematical modelling of the flow process in the industrial installation, the model diagram (Figure 3) was applied. The sulfuric acid installation consists of the following elements: straight sections, $90^{\circ}$ elbows, confusors, diffuser, manual valves, automated control valve, and the flow meter. The mathematical model of the installation of interest is presented above. 


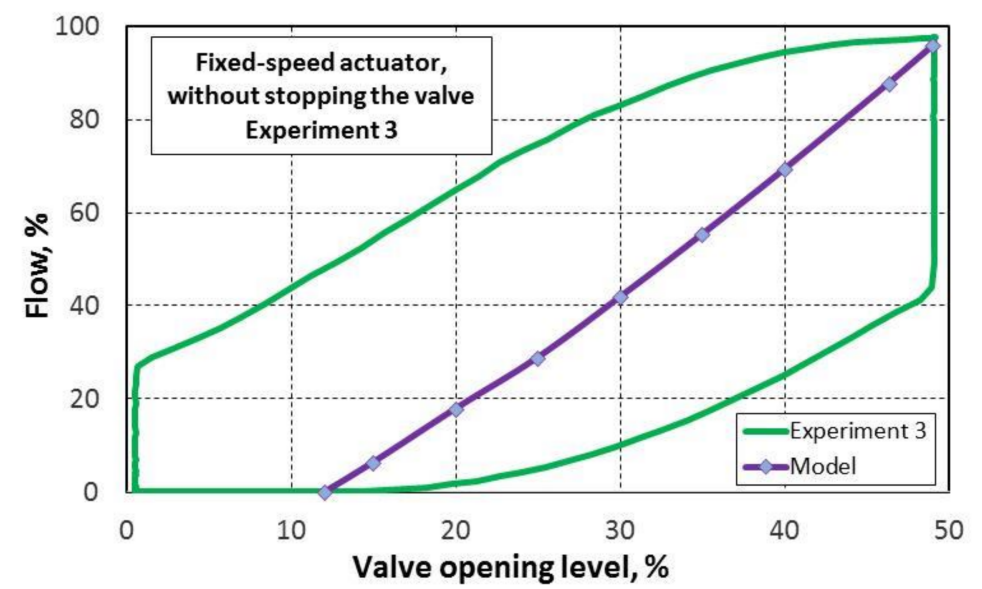

Figure 3. Flow characteristics of the valve with a fixed-speed actuator according to the procedure $(\mathrm{O} / \mathrm{Z})$ along with the model characteristics.

The calculations were performed for the following input parameters: fluid properties, the source (the pump) pressure, and the receiver (a tank with the safety valve) pressure. For the installation discussed, the most difficult issue was determination of the linear resistance coefficients. Figure 4 presents the flow characteristics of the ball valve controlled by the fixed-speed actuator according to the $(\mathrm{O} / \mathrm{Z})$ procedure. This characteristic is "edge-shaped" (as previously discussed), which is not proper for the control system and significantly hampers control procedures. For comparison, the figure also contains the modellingrelated characteristic with a desired course that should be recorded in the real system in case significant inertia of the fluid flow measuring system is absent (passing from the "edge," Experiment 3, to the characteristic's "nerve"-Model).

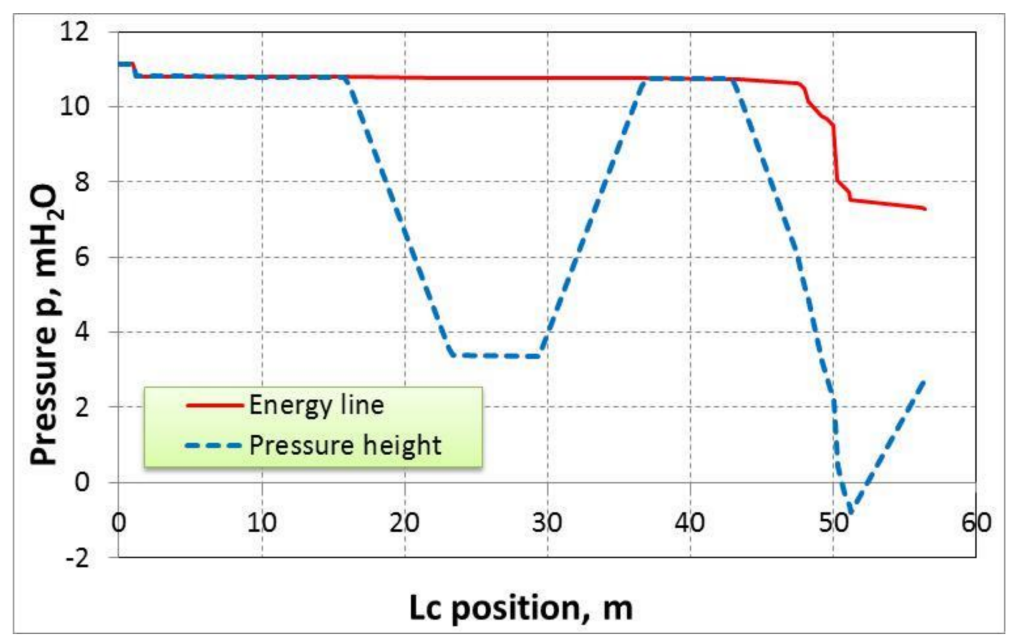

Figure 4. The energy line and the pressure height for the sulfuric acid flow through the installation with the $49 \%$ control valve opening level.

Figure 4 shows energy lines and pressure heights for the $49 \%$ control valve opening level according to the model characteristics of Figure 3. These characteristics result from the Bernoulli's equation being the measure of mechanical energy (expressed in liquid column height units) for the fluid flow. They are included in the mathematical description of the flow system technological flows. The presented energy line was determined for real liquid, and pressure losses were taken into account in the model. These losses are of two types for real fluids: local loss (change in the geometrical shape of the tubing, e.g., valves, elbows, necking) and friction loss (liquid viscosity, flow type, and tubing smoothness). In the presented characteristics, the pressure height value reflects the ratio of static pressure to the 
product of fluid density multiplied by the gravitational acceleration. The pressure height line is shifted against the energy line by the factor called rate height $\mathrm{w}^{2} / 2 \mathrm{~g}$.

\section{Reduced Flow Cross Sectional Area for the Ball Valve vs. Its Opening Angle}

For the issue discussed, the value of flow cross sectional area is a meaningful factor regarding various positions of the ball valve. The value is important when the flow characteristics are formulated to determine the relationship between the fluid flow and the valve opening level. A description of the equation for the reduced flow cross sectional area of the valve vs. its opening angle has been presented in the paper [15], while the final equation is presented below. The reduced flow cross sectional area for the ball valve vs. its opening angle can be described as follows:

$$
\begin{aligned}
a_{p}(\varphi)=\frac{A_{p}(\varphi)}{A_{N}} & =\frac{A_{p}(\varphi)}{\pi R_{N}^{2}} \\
& =\left[\frac{1}{2}-\frac{1}{\pi} \arcsin \left(\sqrt{r^{2}-1} \frac{\cos \varphi}{1+\sin \varphi}\right)\right](1+\sin \varphi) \\
& -\frac{1}{\pi} \sqrt{r^{2}-1} \sqrt{1-\left(r^{2}-1\right)\left(\frac{\cos \varphi}{1+\sin \varphi}\right)^{2}} \cos \varphi
\end{aligned}
$$

where: $a_{p}(\varphi)$-reduced flow cross sectional area for the ball valve vs. its opening angle; $A_{p}(\varphi)$-flow cross sectional areas vs. the opening angle, $\mathrm{m}^{2} ; A_{N}$-nominal flow cross sectional area for the valve, $\mathrm{m}^{2} ; R_{N}$-radius of flow channel diameter $D_{N}, \mathrm{~mm} ; r$-geometric parameter of the ball valve ( $r=D_{k} / D_{N}>1$, where $D_{k}$ is the ball diameter, $\mathrm{mm}$ ).

Following its simplification, the equation for reduced flow cross sectional area of the ball valve vs. its opening angle (opening level) is as follows:

$$
\begin{aligned}
a_{p}(\varphi)=\frac{1}{2}\left[1-\frac{2}{\pi}\right. & \left.\arcsin \left(\sqrt{r^{2}-1} \frac{\cos \varphi}{1+\sin \varphi}\right)\right](1+\sin \varphi) \\
& -\frac{1}{\pi} \sqrt{r^{2}-1} \sqrt{1-\left(r^{2}-1\right)\left(\frac{\cos \varphi}{1+\sin \varphi}\right)^{2}} \cos \varphi
\end{aligned}
$$

\section{Flow Characteristic Investigations for the Model Ball Valve}

For the investigations regarding actuator characteristics, a control ball valve (CBV) was applied with a shaped hole of equal percentage control characteristics. Moreover, a fixed-speed 0-90 NRY24-SR actuator [13] for the valve automated control along with the manual control option was used. The stand diagram is presented in Figure 5, where the following parameters are highlighted: $p$-pressure, $\Delta p$-pressure drop, $\dot{V}$-volumetric fluid flow, $T$-temperature, and $x$-valve opening level. The stand was fitted with several measuring devices, including high-advanced measuring technique equipment (ultrasound, electromagnetic, and sensory), to ensure high measurement precision. In addition, the stand was equipped with the controller and the computer system to modify the experiments according to the own software developed in the industrial LabView environment. 


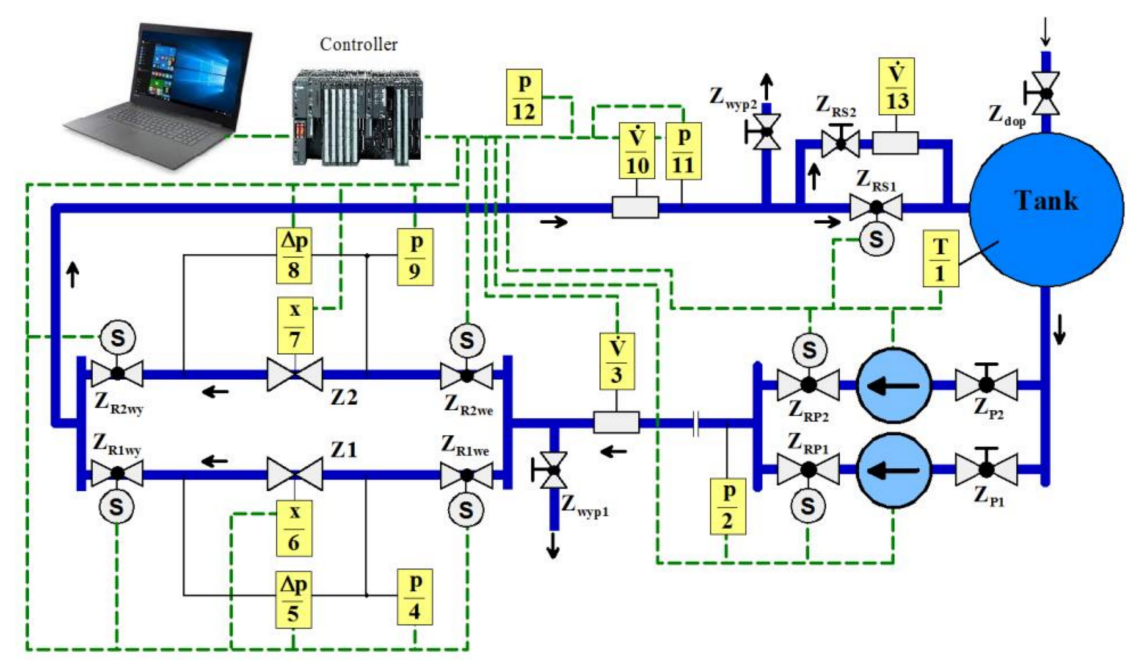

Figure 5. Diagram of the research stand for determining the flow characteristics of valves.

Due to the design solutions, flow characteristics for ball valves contain a dead zone defined as a dead angle $\varphi_{0}$ (16), below which the flow area of the valve equals zero [16]. Thus, the control angle in the ball valve is contained within the range $\varphi \in\left(\varphi_{0}, 90^{\circ}\right)$ and the design of each valve must meet the condition $r_{k} \geq \sqrt{2}$; along with the increasing ratio of the diameters $r_{k}$, the minimum opening angle $\varphi_{0}$ increases:

$$
\varphi_{0}=\arccos \left(\frac{2}{r_{k}^{2}} \sqrt{r_{k}^{2}-1}\right)
$$

where: $r_{k}$-ratio of the ball diameter to the diameter of the delivery port.

For the research, the full operating range of the valve was applied. The research cycle in the prepared procedure involved the automated transition from the closed valve position to its maximum opening, holding it for approx. $40 \mathrm{~s}$, and further performing the closing process with another holding for $40 \mathrm{~s}$. The procedure was specified as the open-close procedure and assigned an $(\mathrm{O} / \mathrm{Z})$ acronym in the automated option. The opening and closing transition time was approx. $35 \mathrm{~s}$ and was consistent with the manufacturer's data.

The experiments under the $(\mathrm{O} / \mathrm{Z})$ procedure resulted in the characteristics presented in Figure $6 a, b$, where it can be observed that: the opening course does not overlap the closing course; the closing course is improper because the ball valves demonstrate the dead angle, which means that no flow is detected below this angle [16]. The estimated dead angle for the $\mathrm{CBV}$ is $\varphi_{0}=16.7^{\circ}$; the CBV characteristics obtained in the laboratory tests (Figure 6a) confirmed the unusual shape of the characteristic resulting from the industrial experiments (Figure 6b). The characteristics presented in Figure 6 are very inconvenient for the fluid flow control processes. In this case, the control system faces significant problems with setting the appropriate value; moreover, so-called pumping is frequently observed in the system. 


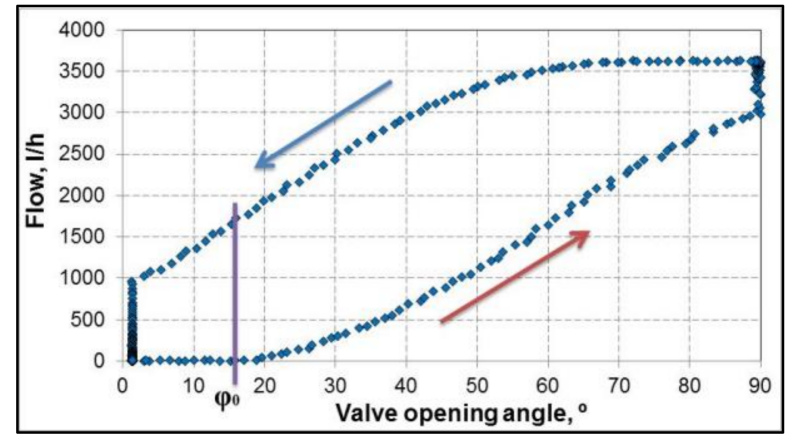

(a)

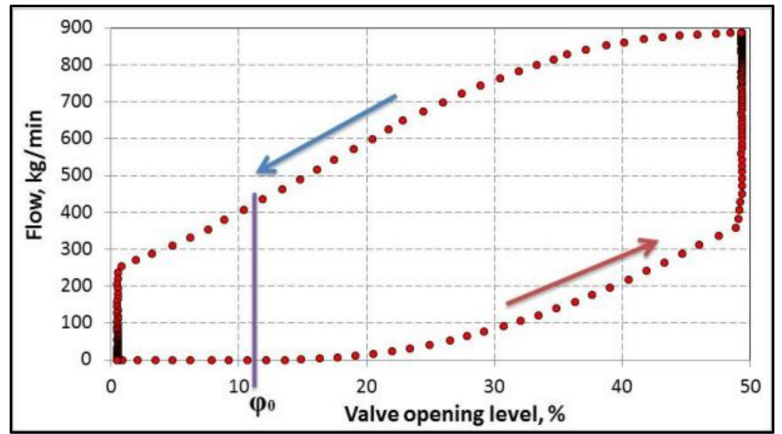

(b)

Figure 6. Test characteristics for the procedure $(\mathrm{O} / \mathrm{Z})$ with indication of the dead angle for: (a) $\mathrm{CBV}$ valve; (b) valve from the industrial system.

To find the explanation for the observed phenomena and contradictions, further experiments were carried out, which involved manual control of the valve through its sudden, complete opening from the closed position, holding for $40 \mathrm{~s}$, and its closing with another holding for $40 \mathrm{~s}$. This research procedure was specified as open-close procedure and assigned the $(\mathrm{O} / \mathrm{Z}) \mathrm{R}$ procedure in the manual system. Based on the results, it was observed that the delay in the flow characteristics was not caused to a high extent by the transducer of the valve angular position. Its response to the position change occurs immediately and the introduced delay is not very meaningful for the whole measuring process. However, it is suggested that the reason of the unusual shape of the characteristics (Figure 6) is the improper flow meter-actuator alignment. The characteristics presented may suggest improper adjustment of the actuator speed and dynamics of the mass flow processing system. Therefore, the analysis of the flow meter dynamics in the $(\mathrm{O} / \mathrm{Z})$ and $(\mathrm{O} / \mathrm{Z}) \mathrm{R}$ procedures was performed, applying the approximation of time characteristics with the use of 1st order inertial function. Based on the results, it was observed that the time constant for the flow meter was too high (approx. $14 \mathrm{~s}$ ), which markedly affected the measurement response time, while the transition time for the actuator between any position points was too short.

To assess effects of the actuator speed on the flow characteristics, a low transition speed actuator should be used or the speed should be reduced if this function is possible to be programmed. Unfortunately, the NRY24-SR is a fixed-speed actuator, so a control procedure was developed to lengthen the time of its full transition, involving short-time actuator stopping within the programmed angular positions. The procedure was specified as the $(\mathrm{O} / \mathrm{Z})$ Stop, and the results of flow meter and actuator dynamics tests are presented in Figure 7. The flow characteristic obtained according to the procedure is presented in Figure 8.

While analysing this characteristic, "approaching" of the courses for the opening and closing operations in the actuator stopping points can be seen. This lets us suppose that with an appropriately low actuator speed or a small time constant for the flow meter, no differences would be observed in the opening and closing processes and both characteristics would overlap. The "contact" points of the valve opening and closing courses can be defined as the characteristic points (Figure 8), which determine the nominal characteristic that should be obtained when the actuator and flow meter are properly selected. 


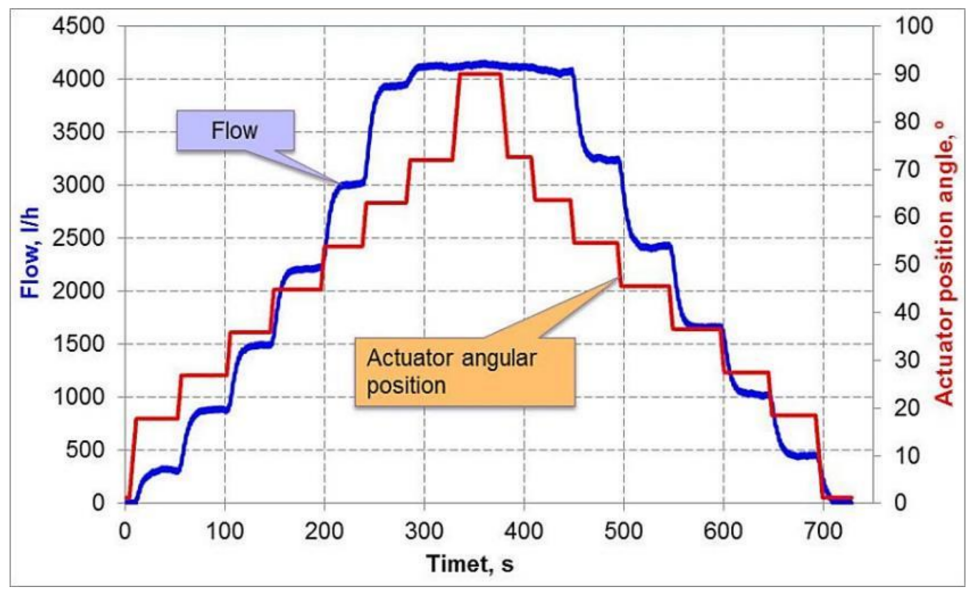

Figure 7. Tests of dynamics of flow meter readings and actuator position angle for $(\mathrm{O} / \mathrm{Z})$ Stop.

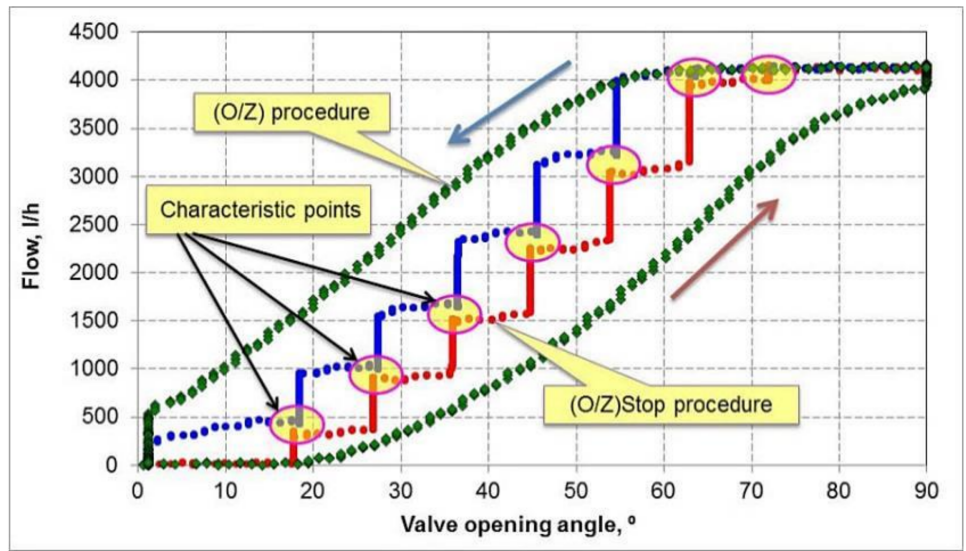

Figure 8. Tests of dynamics of flow meter readings and actuator position angle for $(\mathrm{O} / \mathrm{Z}) \mathrm{Stop}$.

Using the identified characteristic points, the approximating function can be determined. The function will be an approximation of the nominal characteristic and will deliver information about the flow value for the selected valve opening as well as will enable proper control process after its programming into the control system. Based on the measurements, the following approximating function for the characteristic points was proposed:

$$
\dot{V}(\varphi)= \begin{cases}a \varphi^{2}+b \varphi+c & \text { dla } \varphi_{0}<\varphi<50^{\circ} \\ \dot{V}_{\max }\left[1-\exp \left(-\frac{\varphi-\delta}{\gamma}\right)\right] & \text { dla } 50^{\circ} \leq \varphi \leq 70^{\circ}\end{cases}
$$

where: $a, b, c$-function coefficients, respectively: $1 /\left(\mathrm{h}^{\circ 2}\right), 1 /\left(\mathrm{h}^{\circ}\right), 1 / \mathrm{h} ; \varphi_{0}$-dead angle, ${ }^{\circ} ; \dot{V}_{\text {max }}$-maximum technological flow, $1 / \mathrm{h} ; \delta$-function shift value, ${ }^{\circ} ; \gamma$-coefficient of function increment, ${ }^{\circ}$. The coefficients $a, b, c$, and $\delta, \gamma$ are selected individually for each type of ball actuators. They can be determined with the use of appropriate mathematical methods.

The suggested Function (17) is not binding - it is only a proposition. Depending on the characteristic recorded during the initial installation measurements, any other function can be selected. It should be noted that the proposed equation is only recommended for the opening angle range of $70^{\circ}$. In practice, regarding ball valves, the saturation state occurs from at least $60^{\circ}$ up to the maximum opening angle when the flow rate does not actually change its value. Thus, it is an uncontrollable area and should not be considered for automation procedures.

Based on the tests, particularly according to the $(\mathrm{O} / \mathrm{Z})$ Stop procedure, it can be observed that the time constant of the flow meter also considerably affects the characteristics obtained. Therefore, another potential for improvement in the measurement quality is 
reprogramming of the flow meter towards a low time constant provided that this modality is available. If it is not, a device change should be considered, taking into account the proposed guidelines.

The laboratory research stand enables measurements of liquid flow using three methods. One of them applied the MAGFLO ${ }^{\circledR}$, Siemens Flow Instruments A/S electromagnetic flow meter consisting of the MAG5100W flow sensor and the MAG6000 measurement transducer with the measurement precision of $0.25 \%$. The signal transducer demonstrates a potential for setting the time constant of the measurement output within the range of (0.1-30) s [17]. This measuring method corresponds to the industrial installation (Figure 2a); therefore, it was selected for the tests and the analysis.

Effects of the flow meter time constant on the flow characteristic were investigated. The $(\mathrm{O} / \mathrm{Z})$ procedure was applied but to distinguish it, a general acronym $(\mathrm{O} / \mathrm{Z}) \mathrm{T}$ was introduced. The measurements were performed for the following time constants: 10, 5, 2, and $0.1 \mathrm{~s}$; the results are presented in Figure 9.

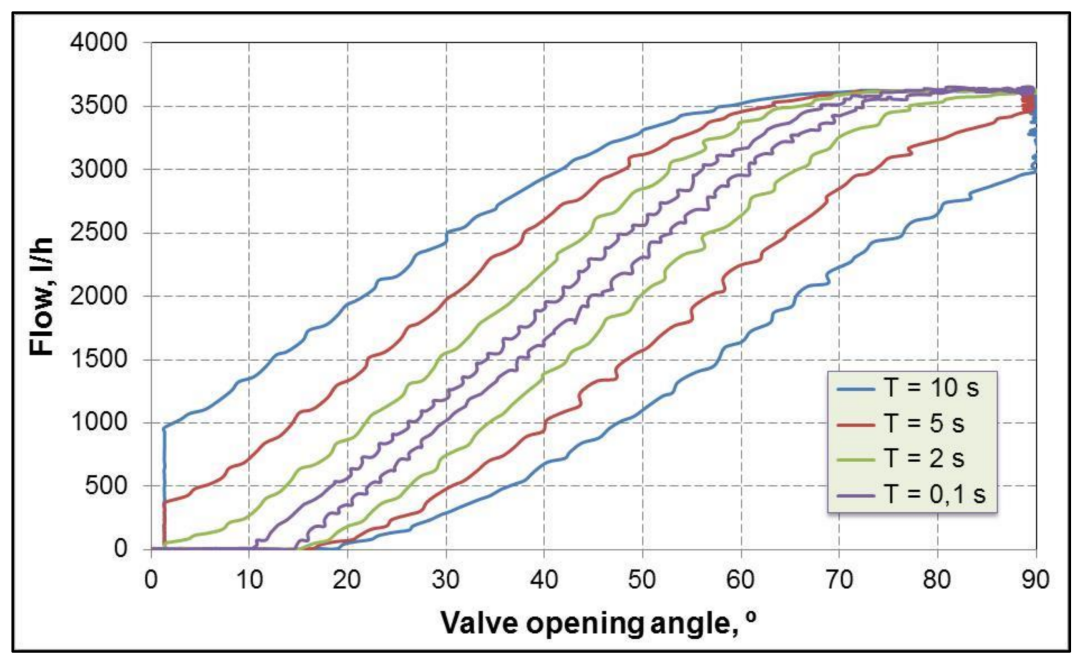

Figure 9. Characteristics of the $(\mathrm{O} / \mathrm{Z}) \mathrm{T}$ procedure for different flow meter time constants.

It can be seen that an increased time constant for the measurement output improves the measuring quality of the device-meaningful reduction of the difference in the readings of the opening and closing courses for the flow characteristic is achieved.

\section{Conclusions}

The analysis of the experimental series showed unusual shapes of sulfuric acid (VI) mass flow characteristics vs. the valve opening level (too wide hysteresis), which markedly deviated from typical flow characteristics that are found in standards and literature. This suggests improper adjustment of the actuator speed and the dynamics of the mass flow processing system.

The proper flow characteristic resulting from the modelling or appropriate selection of the actuator and the fluid flow measuring system shows a positive effect on the control quality, including elimination of the hydraulic pumping phenomenon during positioning.

The short-time stops markedly aligns the flow readings for the opening and closing courses up to their full alignment.

Replacement of the fixed-speed actuator with the variable speed device would considerably improve the shape of the valve flow characteristics. This solution is more convenient compared to the selection of a fixed-speed actuator with the proper transition time.

Application of the faster measurement transducer in the flow meter or reprogramming of the time constant for the measurement output improves the flow characteristics, which ensures a higher quality control process. 
Based on the experiments carried out according to three procedure types: $(\mathrm{O} / \mathrm{Z})$, $(\mathrm{O} / \mathrm{Z}) \mathrm{Stop}$, and $(\mathrm{O} / \mathrm{Z}) \mathrm{T}$, it was demonstrated that improper alignment of the measuring and controlling system in the fluid flow systems results in problems with control procedures; the managing system cannot meet the actuator parameters, which are frequently manifested by the hydraulic pumping phenomenon presence during the actuator positioning.

Author Contributions: Conceptualization, R.Ł. and S.G.; methodology, S.G., M.W. and R.Ł.; software, M.W. and R.Ł.; validation, S.G., M.W. and R.Ł.; formal analysis, S.G., M.W. and R.Ł.; investigation, S.G., M.W. and R.Ł.; resources, M.W. and R.Ł.; data curation, S.G. and M.W.; writing-original draft preparation, S.G., M.W. and R.Ł.; writing—review and editing, S.G., M.W. and R.Ł.; visualization, S.G., M.W. and R.Ł.; supervision, S.G.; project administration, R.Ł.; funding acquisition, R.Ł. All authors have read and agreed to the published version of the manuscript.

Funding: This research received no external funding.

Institutional Review Board Statement: Not applicable.

Informed Consent Statement: Not applicable.

Data Availability Statement: The study did not report any data.

Conflicts of Interest: The authors declare no conflict of interest.

\section{References}

1. Yuan, Q.; Li, P. Using steady flow force for unstable valve design: Modeling and experiments. J. Dyn. Syst. Meas. Control 2005, 127, 451-462. [CrossRef]

2. Rogula, J. The Influence of Seat Fatigue Test on the Leakage in Ball Valve. Procedia Eng. 2012, 39, 91-97. [CrossRef]

3. Amirante, R.; Del Vescovo, G.; Lippolis, A. Evaluation of the flow forces on an open centre directional control valve by means of a computational fluid dynamics analysis. Energy Convers. Manag. 2006, 47, 1748-1760. [CrossRef]

4. Amirante, R.; Moscatelli, P.G.; Catalano, L.A. Evaluation of the flow forces on a direct (single stage) proportional valve by means a computational fluid dynamic analysis. Energy Convers. Manag. 2007, 48, 942-953. [CrossRef]

5. Cho, T.D.; Yang, S.M.; Lee, H.Y.; Ko, S.H. A study on the force balance of an unbalanced globe valve. J. Mech. Sci. Technol. 2007, 21, 814-820. [CrossRef]

6. Valdés, J.R.; Rodríguez, J.M.; Saumell, J.; Pütz, T. A methodology for the parametric modelling of the flow coefficients and flow rate in hydraulic valves. Energy Convers. Manag. 2014, 88, 598-611. [CrossRef]

7. Puszer, A.; Tomeczek, J. A new generation of gaseous media regulating elements for metallurgical heating furnaces. Hutnik 2001, 11, 430-435.

8. Figiel, E.; Szaflik, W. Selection of control valves. Ciepłownictwo Ogrzew. Went. 2006, 1, 12-17.

9. PN-EN 60534-2-3. Industrial Control Valves. Flow Capacity. Test Procedures; PKN: Warszawa, Poland, 2001.

10. Tomeczek, J.; Puszer, A.; Wnęk, M. The method of shaping the regulating characteristics of the flow regulating elements of the fluid stream. Pomiary Autom. Kontrola 2007, 53, 38-43.

11. Wiśniowicz, A. Flow characteristics of the shut-off valves. Gaz Woda Tech. Sanit. 2004, 4, 122-124.

12. Cui, B.; Zhe, Z.; Zhu, Z.; Wang, H.; Ma, G. Influence of opening and closing process of ball valve on external performance and internal flow characteristics. Exp. Therm. Fluid Sci. 2017, 80, 193-202. [CrossRef]

13. PN-76/M-34034. Pipelines. Principles of Calculating Pressure Losses; PKNiM, Wydawnictwo Normalizacyjne: Warszawa, Poland, 1977.

14. DVWK-ATV-A110. Guidelines for the Hydraulic Dimensioning and Proof of Performance of Sewers and Pipes; GFA: Hennef, Germany, 1988.

15. Łudzień, R. Application of Programmable Actuators to Improve the Functioning of Sulfuric Acid (VI) Transport Installations. Ph.D. Thesis, Silesian University of Technology, Katowice, Poland, 2018.

16. Puszer, A.; Wnęk, M. Regulating characteristics of ball valves. Ciepłownictwo Ogrzew. Went. 2012, 1, 33-35.

17. Automatyka Siemens. Available online: www.automatyka.siemens.pl (accessed on 4 December 2020). 